\title{
Hwanggunchungyitang Prevents Cadmium-Induced Ototoxicity through Suppression of the Activation of Caspase-9 and Extracellular Signal-Related Kinase in Auditory HEI-OC1 Cells
}

\author{
Su-Jin KIm, ${ }^{a, e, \#}$ Bong-Gi SHIN, ${ }^{a, \#}$ In-Young CHoI, ${ }^{a}$ Dong-Hyun KIm, ${ }^{a}$ Min-cheol KIm, ${ }^{a}$ \\ Noh-Yil Myung, ${ }^{d}$ Phil-Dong Moon, ${ }^{e}$ Jeong-Han LeE, ${ }^{a}$ Hyo-Jin An, ${ }^{e}$ Na-Hyung KIm, ${ }^{e}$ \\ Joo-Young LeE, ${ }^{b}$ Hong-seob So, ${ }^{a}$ Rae-Kil PARK, ${ }^{a}$ Hyun-Ja JeOng, ${ }^{c}$ Jae-Young UM, ${ }^{d, e}$ \\ Hyung-Min KIM, ${ }^{e}$ and Seung-Heon HonG ${ }^{*}, a, f$ \\ ${ }^{a}$ VestibuloCochlear Research Center of Wonkwang University; ${ }^{f}$ Department of Oriental Pharmacy, College of Pharmacy, \\ Wonkwang University; Iksan, Jeonbuk 570-749, Republic of Korea: ${ }^{b}$ Department of Herb Science, ShinSung College; \\ Chungnam 343-861, Republic of Korea: ${ }^{c}$ Biochip Research Center, Hoseo University; 165, Sechul-ri, Baebang-myun, \\ Asan, Chungnam 336-795, Republic of Korea: ${ }^{d}$ Acupuncture and Meridian Science Research Center, Kyung Hee \\ University; and ${ }^{e}$ College of Oriental Medicine, Kyung Hee University; 1 Hoegi-Dong, Dongdaemun-Gu, Seoul 130-701, \\ Republic of Korea. Received July 28, 2008; accepted November 10, 2008
}

Hwanggunchungyitang (HGCYT) is a newly designed herbal drug formula for the purpose of treating auditory diseases. A number of heavy metals have been associated with toxic effects to the peripheral or central auditory system. Cadmium $\left(\mathrm{Cd}^{2+}\right)$ is a heavy metal and a potent carcinogen implicated in tumor development through occupational and environmental exposure. However, the auditory effect of $\mathrm{Cd}^{2+}$ is not poorly understood. The purpose of the present study was to investigate whether HGCYT prevent the ototoxic effects induced by $\mathrm{Cd}^{2+}$ in auditory cell line, HEI-OC1. HGCYT inhibited the cell death, reactive oxygen species generation (ROS), activation of caspase-9, and extracellular signal-related kinase (ERK) induced by $\mathrm{Cd}^{2+}$. In addition, we observed that cochlear hair cells in middle turn were damaged by $\mathrm{Cd}^{2+}$. However, HGCYT prevented the destruction of hair cell arrays of the rat primary organ of Corti explants in the presence of $\mathrm{Cd}^{2+}$. These results support the notion that ROS are involved in $\mathrm{Cd}^{2+}$ ototoxicity and suggest HGCYT therapeutic usefulness, against $\mathrm{Cd}^{2+}$-induced activation of caspase-9 and ERK.

Key words Hwanggunchungyitang; cadmium; auditory cell; caspase-9; extracellular signal-related kinase

Cadmium $\left(\mathrm{Cd}^{2+}\right)$ is a major environment and occupational hazard because of its widespread use in industry and subsequent release into the environment. Irreversible hearing loss is a characteristic effect of a number of heavy metals. The high incidence of hearing loss in human who reside in industrialized countries was increased. ${ }^{1-5)}$ Other experimental study showed that $\mathrm{Cd}^{2+}$ also has a dose-dependent deleterious effect on the auditory system. ${ }^{6} \mathrm{Cd}^{2+}$ toxicity has been described as in vitro and in vivo apoptosis but its molecular mechanism in auditory system is not fully understood.

Although $\mathrm{Cd}^{2+}$ can activate various signaling pathways, mitochondria are the most pertinent in mediating apoptosis via reactive oxygen species (ROS) generation. ${ }^{7,8)}$ Recent studies suggest that ROS generation associated with $\mathrm{Cd}^{2+}$ exposure leads to oxidative stress, which is an important factor involved in $\mathrm{Cd}^{2+}$-induced apoptosis. ${ }^{9,10)} \mathrm{Cd}^{2+}$-induced loss of mitochondrial membrane potential (MMP) may be a spontaneous event at early stages of apoptosis causing membrane perturbations leading to cytochrome (cyt) $c$ release. ${ }^{11)}$ Which apoptotic pathway is induced by $\mathrm{Cd}^{2+}$ remains controversial. Some studies strongly suggest that caspases play a central role in $\mathrm{Cd}^{2+}$-induced cell death. ${ }^{12-14)}$ Numerous other studies suggest a caspase-independent mechanism. ${ }^{15-17)}$ It is conceivable that $\mathrm{Cd}^{2+}$ may induce different apoptotic pathways in different cell types and in dependence on the exposure (cell treatment) conditions.

Mitogen-activated protein kinases (MAPKs) belong to a family of Ser/Thr protein kinases that transmit extracellular signals into the nucleus. There are three subfamilies of
MAPKs including c-Jun NH2-terminal kinase (JNK; also known as stress-activated protein kinase), p38 MAPK, and extracellular signal-related kinase (ERK) ${ }^{18)}$ In general, the ERK signaling cascade is activated by growth factors and is associated with cell survival and proliferation. ${ }^{19,20)}$ On the other hand, p38 and JNK are mainly activated by cellular stress and are often associated with inflammation and apoptosis. However, cumulative reports have indicated that these signaling pathways exhibit more complex roles in the regulation of distinct cellular effects. The cellular functions regulated by ERK, p38 or JNK seem to depend on the cell type, the stimulus, the duration and strength of kinase activities. For example, the ERK activation is involved in $\mathrm{Cd}^{2+}$-induced G2/M arrest and cell death in CCRF-CEM cells. ${ }^{21)}$ But the ERK1/2 pathway was not responsible for $\mathrm{Cd}^{2+}$-induced cytotoxicity in CL3 cells, a lung carcinoma cell line. ${ }^{22)}$ Also, it was reported that $\mathrm{Cd}^{2+}$ induced apoptosis through the activation of $\mathrm{JNK}$, but no activation of $\mathrm{p} 38$ in $\mathrm{J} 774 \mathrm{~A} .1$ cells. $^{23}$ ) Taken together, these reports suggest that the discrepancies in MAPKs activation and $\mathrm{Cd}^{2+}$-induced apoptosis may be due to difference in cell type.

Hwanggunchungyitang (HGCYT) formula is a newly modified prescription for the purpose of development of auditory disease. HGCYT is composed of 9 oriental herbs. In the present study, we investigate the protective effects of HGCYT against $\mathrm{Cd}^{2+}$-induced ototoxicity in auditory HEIOC1 cells. In addition, the protective effects of HGCYT against $\mathrm{Cd}^{2+}$-induced hair cell damage have been investigated in organ of Corti. 


\section{MATERIALS AND METHODS}

Reagents Fetal bovine serum (FBS), and high-glucose Dulbecco's modified Eagle's medium (DMEM) were purchased from GIBCO BRL (Grand Island, NY, U.S.A.). SB203580, PD98059 and SP600125 were purchased from Calbiochem (St. Louis, MO, U.S.A.). H2DCF-DA was obtained from Molecular Probes (Leiden, The Netherlands). Dimethyl sulfoxide (DMSO), 3-(4,5-dimethylthiazol-2-yl)2,5-diphenyltetrazolium bromide (MTT) and other reagents were purchased from Sigma Chemical (St. Louis, MO, U.S.A.). Cytochrome $c$, caspase-9, ERK, and cyclooxigenase-2 (COX-2) antibody was obtained from Santa Cruz Biotechnology, Inc. (Santa Cruz, CA, U.S.A.).

Preparation of HGCYT An extract of HGCYT which is a mixture of 9 traditional drugs as shown in Table 1 was obtained from the College of Pharmacy, Wonkwang University (Iksan, South Korea). Amounts of the 9 traditional drugs studied in this work were shown in Table 1. Extract of HGCYT was prepared by decocting the dried description of herbs with boiling distilled water. The extraction decocted for approximately $3 \mathrm{~h}$ has been filtered, lyophilized, and kept at $4{ }^{\circ} \mathrm{C}$. The yield of extraction was about $4.85 \%$. Dilutions were made in saline then filtered through $0.45-\mu \mathrm{m}$ syringe filter.

Cell Culture The HEI-OC1 cell line was a kind gift from Dr. Federico Kalinec (House Ear Institute, Los Angeles, CA, U.S.A.). Establishment of immortal cell lines was facilitated by a transgenic mouse, Immortomouse ${ }^{\mathrm{TM}}$ (Charles River Laboratories, Wilmington, MA, U.S.A.), which harbors a temperature-sensitive mutant of the SV40 large T antigen gene under the control of an interferon-gamma-inducible promoter element. Cochlear half turns from Immortomice at postnatal day 7 were cultured on uncoated plastic culture dishes under permissive conditions $\left(33^{\circ} \mathrm{C}\right)$ in antibiotic-free DMEM (Gibco BRL, Grand Island, NY, U.S.A.) containing $10 \%$ FBS (JRH Bioscience, Lenexa, KS, U.S.A.) and $50 \mathrm{U} / \mathrm{ml}$ gamma-interferon. Cochlear explants were placed at different times in non-permissive conditions $\left(39^{\circ} \mathrm{C}\right)$ and allowed to differentiate for up to $180 \mathrm{~d}$. Cultures were monitored on a daily basis by phase-contrast and video microscopy. Explants, cells growing in tissue regions formerly associated with the organ of Corti, were isolated by lifting with a micropipette after 2 to 5 min incubation with trypsinEDTA. A cell line, named HEI-OC1, was cloned in the absence of antibiotics, using the limiting dilution method and characterized by observation with phase contrast light microscopy, Western blotting and immunofluorescence. Cells

Table 1. Prescription of HGCYT

\begin{tabular}{|c|c|}
\hline Hwanggunchungyitang components & Ratio \\
\hline 1. Glycyrrhizae Radix & 2 \\
\hline 2. Zingiberis Rhizoma & 4 \\
\hline 3. Angelicae Gigantis Radix & 4 \\
\hline 4. Rehmanniae Radix & 6 \\
\hline 5. Mori Cortex & 4 \\
\hline 6. Aurantii Fructus & 4 \\
\hline 7. Citri Pericarpium & 4 \\
\hline 8. Gardeniae Fructus & 4 \\
\hline 9. Scutellariae Radix & 6 \\
\hline
\end{tabular}

were maintained in DMEM medium with $10 \%$ fetal bovine serum at $33{ }^{\circ} \mathrm{C}$ under $5 \% \mathrm{CO}_{2}$ in air. HEI-OC1 cells express several molecular markers characteristic of organ of Corti sensory cells: thyroid hormone, brain-drived neurotrophic factor, calbindin, calmodulin, Connexin 26, Math 1, Myosin $7 \mathrm{a}$, organ of Corti protein 2 , tyrosin kinase receptors B and $\mathrm{C}$, platelet-derived growth factor receptor, and prestin. In addition, HEI-OC1 cells are extremely sensitive to ototoxic drugs. ${ }^{24)}$

MTT Assay To test the viability of cells, MTT colorimetric assay was performed as described previously. ${ }^{25}$ Briefly, Cells $\left(3 \times 10^{5}\right.$ cells/well) were exposed to various concentrations of HGCYT and then treated with $\mathrm{Cd}^{2+}$. After incubation, MTT solution $(5 \mathrm{mg} / \mathrm{ml}$ in phosphate buffered saline (PBS)) was added ( $50 \mu \mathrm{l} /$ well), and plates were further incubated for $4 \mathrm{~h}$ at $33{ }^{\circ} \mathrm{C}$. Precipitated formazan crystals were centrifuged and the pellets were dissolved by the addition of dimethyl sulfoxide (DMSO). Absorption was measured by spectrometer at $540 \mathrm{~nm}$.

Measurement of Caspase-9 Activity The enzymatic activity of caspase-9 was assayed using the caspase colorimetric assay kit (R\&D Systems, Minneapolis, MN, U.S.A.) according to the manufacturer's protocol. Briefly, cells were left untreated or treated with $\mathrm{Cd}^{2+}$ for $24 \mathrm{~h}$ and then lysed in lysis buffer for $10 \mathrm{~min}$ on ice. The lysed cells were centrifuged at $14000 \mathrm{rpm}$ for $5 \mathrm{~min}$, and protein was incubated with $50 \mu \mathrm{l}$ reaction buffer and $5 \mu \mathrm{l}$ caspase- 9 substrate at $37^{\circ} \mathrm{C}$ for $2 \mathrm{~h}$, and the absorbance was measured at a wavelength of $405 \mathrm{~nm}$ on a plate reader. Equal amount of total protein was quantified by bicinchoninic acid (BCA) protein quantification kit (Sigma) in each lysate.

Measurement of Intracellular ROS Generation Intracellular ROS levels were measured using a fluorescent dye, 2', 7'-dichlorofluorescein diacetate (DCFH-DA; Eastman Kodak, Rochester, NY, U.S.A.). In the presence of an oxidant, DCFH is converted into a highly fluorescent molecule, $2^{\prime}, 7^{\prime}$-dichlorofluorescein (DCF). HEI-OC1 cells were cultured overnight on round coverslips, and then treated with $\mathrm{Cd}^{2+}$. Cells were washed twice with serum-free, phenol redfree medium, and incubated for $30 \mathrm{~min}$ with $5 \mu \mathrm{M}$ DCFH-DA in serum-free, phenol red-free medium medium. Fluorescence intensity was measured in a spectrofluorometer at excitation $485 \mathrm{~nm}$ and emission $538 \mathrm{~nm}$.

Western Blot Analysis For analysis of the levels of COX-2, caspase-9, cyt $c$, cells were rinsed twice with icecold PBS and were then lysed in ice-cold lysis buffer $(1 \%$ Triton, 1\% Nonidet P-40, 0.1\% SDS, 1\% deoxycholate in PBS). Cell lysates were centrifuged at $15000 \boldsymbol{g}$ for $5 \mathrm{~min}$ at $4{ }^{\circ} \mathrm{C}$; the supernatant was then mixed with an equal volume of $2 \times \mathrm{SDS}$ sample buffer, boiled for $5 \mathrm{~min}$, and then separated through $10 \%$ sodium dodecyl sulfate-polyacrylamide gel electrophoresis (SDS-PAGE) gels. After electrophoresis, the protein was transferred to nylon membranes by electrophoretic transfer. The membranes were blocked in $5 \%$ skim milk for $2 \mathrm{~h}$, rinsed, and incubated overnight at $4{ }^{\circ} \mathrm{C}$ with primary antibodies in $\mathrm{PBS} / 0.5 \%$ Tween 20 . Excess primary antibody was then removed by washing the membranes four times in PBS/0.5\% Tween 20, and the membranes were incubated for $1 \mathrm{~h}$ with HRP-conjugated secondary antibodies (against mouse, goat, or rabbit). After three washes in PBS $/ 0.5 \%$ Tween 20 , the protein bands were visualized by an 
enhanced chemiluminescence assay (Amersham Pharmacia Biotech, NJ, U.S.A.) following the manufacturer's instructions.

Organ of Corti Explant Culture The organ culturing procedure was similar to that described previously. ${ }^{26}$ Sprague Dawley rats were sacrificed on postnatal day 2 and the cochlea were carefully removed by dissection. The stria vascularis and spiral ligament were removed leaving the organ of Corti. The basal, middle, and apex turns of the cochlea were used for further study. Cochlear explants were treated with high glucose $(4.5 \mathrm{~g} / \mathrm{l})$ DMEM containing $10 \%$ FBS, $\mathrm{Cd}^{2+}$, or the combination of $\mathrm{Cd}^{2+}$ and HGCYT, and incubated for $24 \mathrm{~h}$ at $37^{\circ} \mathrm{C}, 5 \% \mathrm{CO}_{2}$. When experimental treatment was completed, the culture was prepared for histological analysis. Organ of Corti explants were fixed at RT for $15 \mathrm{~min}$ in $2 \%$ paraformaldehyde in PBS. Specimens were rinsed in PBS, incubated in $0.25 \%$ Triton X-100 for 2 min and immersed in Tetramethylrhodamine isothiocyanate (TRITC)-labeled phalloidin (Sigma, 1:100 diluted) in PBS for $20 \mathrm{~min}$. After rinsing three times with PBS, specimens were examined under a fluorescence microscope with appropriate filters appropriate for TRITC (excitation: 510 $550 \mathrm{~nm}$, emission: $590 \mathrm{~nm}$ ). This work was carried out in conformity with all applicable regulations and institutional use rules of Laboratory Animal in Wonkwang University School of Medicine.

Statistical Analysis The experiments shown are a summary of the data from at least-three experiments and are presented as the mean \pm S.E.M. Statistical evaluation of the results was performed by ANOVA with Tukey post hoc test. The results were considered significant at a value of $p<0.05$.

\section{RESULTS}

The Effect of HGCYT on $\mathrm{Cd}^{2+}$-Induced Cell Viability in HEI-CO Cells First, the effect of $\mathrm{Cd}^{2+}$ on the viability of HEI-OC1 cells was investigated. Cells were incubated with different concentrations of HGCYT $(0.01-1 \mathrm{mg} / \mathrm{ml})$ and then treated with $\mathrm{Cd}^{2+}(10 \mu \mathrm{M})$ for $24 \mathrm{~h}$. Cell viability was measured using MTT assay. As shown Fig. 1, when the cells were treated for $24 \mathrm{~h}$ with $\mathrm{Cd}^{2+}$, the cell viability significantly decreased. However, HGCYT inhibited $\mathrm{Cd}^{2+}$-induced cell death on the HEI-OC1 cells in a dose-dependent manner.

The Effect of HGCYT on ROS Generation in HEI-CO Cells Mitochondria are a regular source of ROS, but an increase in the rate of ROS production can damage the mitochondrial membrane leading to apoptosis. Thus, we examined whether HGCYT affected the $\mathrm{Cd}^{2+}$-induced intracellular ROS generation. Cells were incubated with or without HGCYT and loaded with DCF-DA, which is converted into a fluorescent molecule after intracellular oxidation. As shown in Fig. 2, treatment of $\mathrm{Cd}^{2+}$ significantly increased the generation of intracellular ROS. However, it was found that HGCYT $(0.01-1 \mathrm{mg} / \mathrm{ml})$ inhibited these increased ROS level in dose-dependent manner.

The Effect of HGCYT on Cyt $c$ Release, COX-2, Metallothionein (MT) Expression in HEI-CO Cells Cyt $c$ is released following mitochondrial membrane permeabilization, and plays a major role in cell death. ${ }^{27)}$ To determine the effect of HGCYT on cyt $c$ release from mitochondrial into the cytosol, Western blot analysis was performed. As shown in

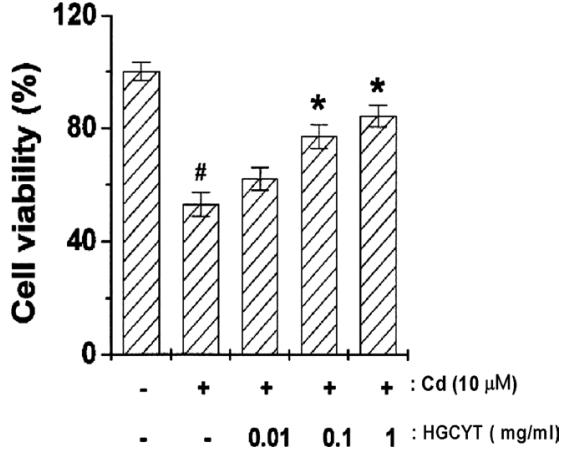

Fig. 1. The Effect of $\mathrm{Cd}^{2+}$ on Cell Viability in HEI-OC1

Cells $\left(3 \times 10^{5}\right)$ were pretreated with $\operatorname{HGCYT}(0.01-1 \mathrm{mg} / \mathrm{ml})$ and treated with $\mathrm{Cd}^{2+}$ for various concentrations $(10 \mu \mathrm{M})$ for $24 \mathrm{~h}$. Cell viability was evaluated by MTT colorimetric assay. Data represent the mean \pm S.E.M. of three independent experiments performed in duplicate. $\# p<0.05$, significantly different from not-treated cells. $* p<0.05$, significantly different from $\mathrm{Cd}^{2+}$ alone-treated cells.

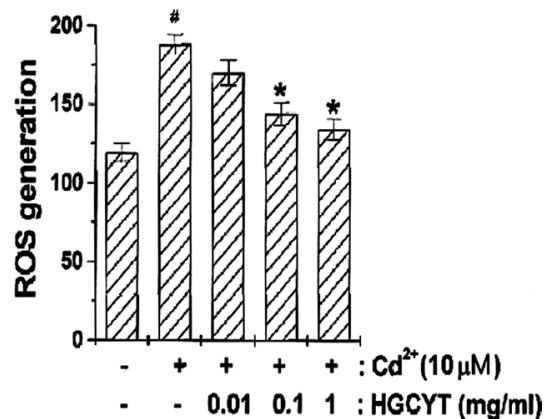

Fig. 2. The Effect of HGCYT on ROS Production in HEI-OC1

Cells $\left(3 \times 10^{5}\right)$ were pretreated with HGCYT $(0.01-1 \mathrm{mg} / \mathrm{ml})$ and treated with $\mathrm{Cd}^{2+}$ for concentrations $(10 \mu \mathrm{M})$ for $24 \mathrm{~h}$. After experiment, cells were loaded with the fluorescent probe DCFH-DA and fluorescence was measured in a spectrofluorometer. Data represent the mean \pm S.E.M. of three independent experiments performed in duplicate \# $p<0.05$, significantly different from not-treated cells. $* p<0.05$, significantly different from $\mathrm{Cd}^{2+}$ alone-treated cells.

Fig. 3A, treatment of $\mathrm{Cd}^{2+}$ significantly induced the release of cyt $c$ to the cytosol. We found that the release of cyt $c$ was inhibited by pretreatment of HGCYT in dose-dependent manner. The relative intensity of the cyt $c$ expression level was quantitated by densitometry (Fig. 3B).

Recently, other reports demonstrated that the COX-2 enzyme is constitutively expressed in the organ of Corti and spiral ganglion cells of the guinea pig cochlea. ${ }^{28)}$ In order to gain insight into a possible role of COX-2 in physiological processes, we determined $\mathrm{COX}-2$ expression after $\mathrm{Cd}^{2+}$ treatment, and assay the regulatory effect of HGCYT. Data in Fig. 3C, the result showed that $\mathrm{Cd}^{2+}$ induced the level of COX-2 compared with un-stimulated cells. This enhanced level of COX-2 was inhibited by pretreatment of HGCYT in a dose-dependent manner. The relative intensity of the COX2 expression level was quantitated by densitometry (Fig. 3D).

MT is a ubiquitous metalloprotein found in bacteria, mammals and invertebrates. Although the exact function of MT is unknown, it has been suggested MT is involved in toxic metal detoxification. To determine the effect of HGCYT on MT expression, Western blot analysis was performed. As shown in Fig. 3E, treatment of $\mathrm{Cd}^{2+}$ induced the MT expression. We found that the expression of MT was not affected by HGCYT.

The Effect of HGCYT on Caspase-9 Activation in HEI- 
A)

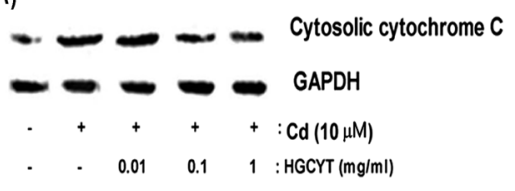

C)

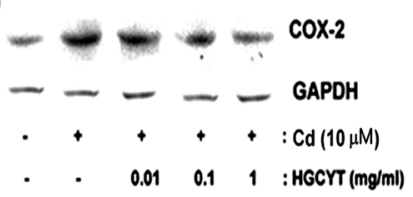

E)

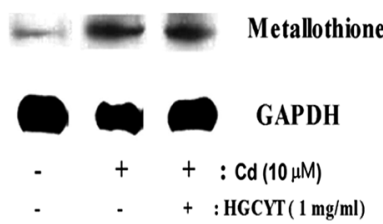

B)

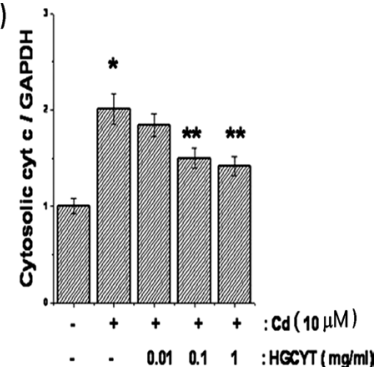

D)

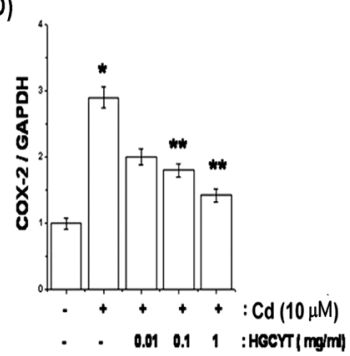

Fig. 3. The Effect of HGCYT on Apoptosis Associated Genes in HEI-COI Cells

Cells $\left(5 \times 10^{6}\right)$ were pretreated with HGCYT $(0.01-1 \mathrm{mg} / \mathrm{ml})$ and treated with $\mathrm{Cd}^{2+}$ for various concentrations $(10 \mu \mathrm{M})$ for $24 \mathrm{~h}$. (A) The protein extracts were assayed for cyt $c$ by Western blot analysis. (B) The relative levels of the cytosolic cyt $c$ were quantitated by densitometry. (C) The protein extracts were assayed for COX-2 by Western blot analysis. (D) The relative levels of the cytosolic COX-2 were quantitated by densitometry. (E) The protein extracts were assayed for MT by Western blot analysis. Figures are representative data of three independent experiments.

A)

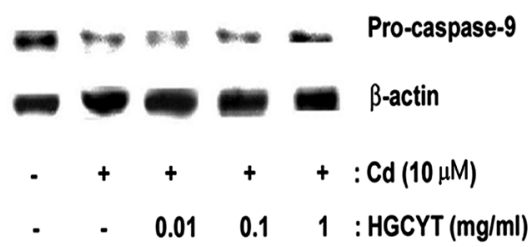

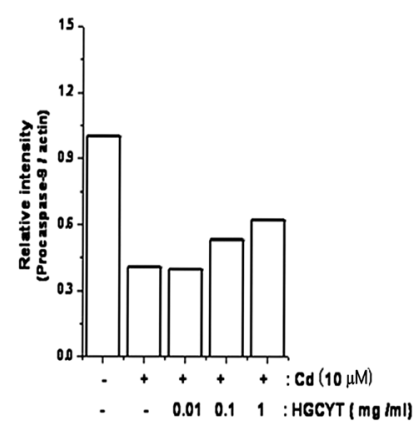

B)

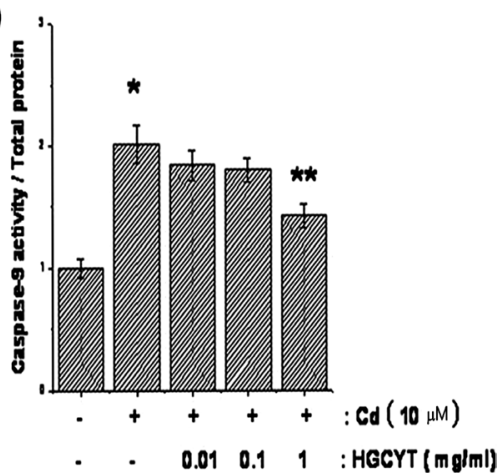

Fig. 4. The Effect of $\mathrm{Cd}^{2+}$ on Caspase-9 Activity in HEI-COI Cells

(A) Cells $\left(5 \times 10^{6}\right)$ were pretreated with HGCYT $(0.01-1 \mathrm{mg} / \mathrm{ml})$ and treated with $\mathrm{Cd}^{2+}$ for various concentrations $(10 \mu \mathrm{M})$ for $24 \mathrm{~h}$. The protein extracts were assayed by Western blot analysis for pro-caspase-9. (B) Caspase-9 activities were determined by a colorimetric kit using substrates, as described under Materials and Methods. Data represent the mean \pm S.E.M. of three independent experiments performed in duplicate. $* p<0.05$, significantly different from not-treated cells. $* * p<0.05$, significantly different from Cd ${ }^{2+}$ alone-treated cells.

CO Cells Pro-apoptotic stimuli induce mitochondrial membrane permeabilization and promote release of cyt $c$ in the cytosol leading to actvation of pro-apoptotic factors as well as the maturation of caspase-9. ${ }^{29)}$ In the present study, the extent to which HGCYT influences the caspase-9 activity was investigated. Cells were pretreated with HGCYT $(0.01-$ $1 \mathrm{mg} / \mathrm{ml})$ for $1 \mathrm{~h}$, and then treated with $\mathrm{Cd}^{2+}(10 \mu \mathrm{M})$ for $24 \mathrm{~h}$. As shown in Fig. 4A, we observed that $\mathrm{Cd}^{2+}$ decreased the pro-caspase-9 expression, an inactive form of caspase-9. However, HGCYT inhibited the phenomenon in $\mathrm{Cd}^{2+}$-induced HEI-OC1 cells. The relative intensity of the pro-caspase- 9 expression level was quantitated by densitometry.
Next, to confirm whether HGCYT inhibited the caspase-9 activation, a caspase assay kit was used. As shown in Fig. 4B, $\mathrm{Cd}^{2+}$ induced the caspase- 9 activation, these increase level was inhibited by the treatment of HGCYT in a dose-dependent manner.

The Effect of HGCYT on ERK Activation in HEI-CO Cells In order to explore whether HGCYT influences the MAPK pathways in $\mathrm{Cd}^{2+}$-induced apoptosis, inhibitors of PD98059 (ERK inhibitor), SB202190 (p38 inhibitor), and SP600125 (JNK inhibitor) were used. As shown in Fig. 5A, ERK inhibitor was observed to effectively suppress $\mathrm{Cd}^{2+}$ induced the cell death. Based on the results showing the in- 

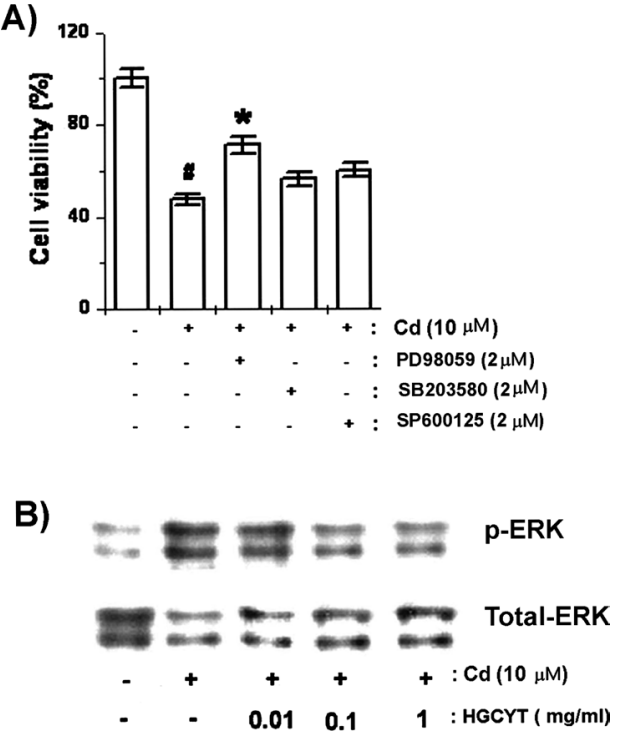

Fig. 5. The Effect of HGCYT on ERK Activation in HEI-COI Cells

(A) Cells $\left(3 \times 10^{5}\right)$ were pretreated with PD98059 $(2 \mu \mathrm{M})$, SB203580 $(2 \mu \mathrm{M})$, and SP600125 $(2 \mu \mathrm{M})$ were pretreated for $1 \mathrm{~h}$, and then treated with $\mathrm{Cd}^{2+}(10 \mu \mathrm{M})$ for $24 \mathrm{~h}$. Cell viability was evaluated by MTT colorimetric assay. (B) Cells were pretreated with HGCYT $(0.01-1 \mathrm{mg} / \mathrm{ml})$ and treated with $\mathrm{Cd}^{2+}(10 \mu \mathrm{M})$ for $24 \mathrm{~h}$. The protein extracts were assayed or phospho-ERK and total ERK by Western blot analysis. Data represen the mean \pm S.E.M. of three independent experiments performed in duplicate. $\# p<0.05$, significantly different from not-treated cells. $* p<0.05$, significantly different from $\mathrm{Cd}^{2+}$ alone-treated cells.

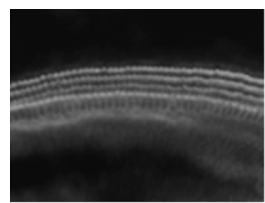

1

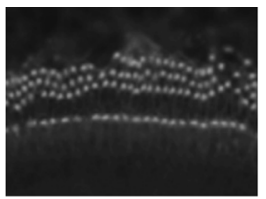

2

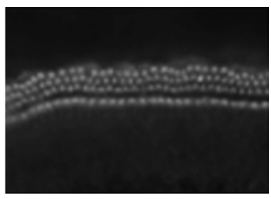

3
Fig. 6. The Effect of HGCYT in the Primary Organ of Corti Explants against $\mathrm{Cd}^{2+}$

The middle turns of the cochlea were used. The organ of Corti explants were pretreated with HGCYT $(1 \mathrm{mg} / \mathrm{ml})$ for $1 \mathrm{~h}$ and then treated with $\mathrm{Cd}^{2+}$. The organ of Corti explants were fixed with paraformaldehyde, and stained with TRITC-conjugated phalloidin, and then observed under fluorescent microscope. 1) Control; 2) $\mathrm{Cd}^{2+}$ treatment; 3) HGCYT $(1 \mathrm{mg} / \mathrm{ml})+\mathrm{Cd}^{2+}$. Figures are representative data of three independent experiments.

hibitory effect of ERK inhibitor on $\mathrm{Cd}^{2+}$-induced cell death, we examined whether HGCYT regulate activation of ERK during apoptosis. As shown in Fig. 5B, it was found that $\mathrm{Cd}^{2+}$ induced ERK activation, but HGCYT inhibited these increased ERK activation in dose-dependent manner.

The Protective Effect of HGCYT in the Primary Organ of Corti Explants against $\mathbf{C d}^{2+}$ The following experiments were designed to determine whether HGCYT could protect the rat organ of Corti primary explants. The organ of Corti from rats was isolated and treated with $\mathrm{Cd}^{2+}$ in the absence or presence of HGCYT. Phalloidin, which binds to Factin, was used as a marker to identify surviving hair cells in cochlear explant cultures which are highly enriched in the stereociliary bundles of hair cells. TRITC-conjugated phalloidin-labeled stereochilia bundles in outer hair cells (OHCs) and inner hair cells (IHCs) facilitated easy identification of hair cells. The orderly arrangement of the three rows of OHCs and a single row of IHCs in a conrol tissue is shown in Fig. 6. When compared with the control, treatment of $\mathrm{Cd}^{2+}$ into culture medium resulted in loss of F-actin staining-posi-

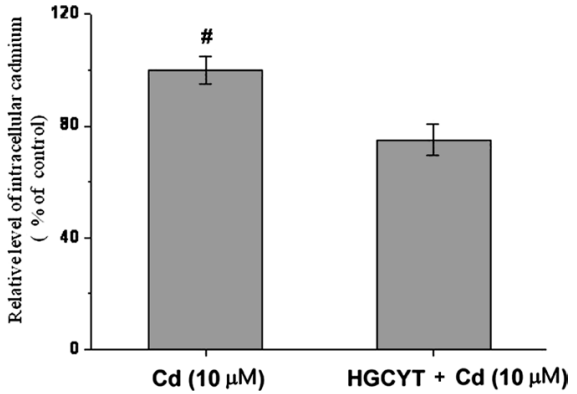

Fig. 7. The Effect of HGCYT on the Accumulation of Intracellular $\mathrm{Cd}^{2+}$ within Cells

Cells were pretreated with HGCYT $(1 \mathrm{mg} / \mathrm{ml})$ and treated with $\mathrm{Cd}^{2+}(10 \mu \mathrm{M})$ for $24 \mathrm{~h}$. After experiment, cells were dissolved with diluted $\mathrm{HNO}_{3}$. Cd measurements were performed using optical emission spectrometry via ICP/OES. Standards were prepared as increasing amounts of cadmium standards in deionized water each containing $20 \%$ of digested cells. Data represent the mean \pm S.E.M. of three independent experiments performed in duplicate. $\# p<0.05$, significantly different from not-treated cells.

tive cells and the disarray of most stereocilia bundles of hair cells, especially OHCs. These data showed that cochlear hair cells were damaged by $\mathrm{Cd}^{2+}$. However, pretreatment with the HGCYT prevented the destruction of hair cell arrays of the rat primary organ of Corti explants in the presence of $\mathrm{Cd}^{2+}$.

The Effect of HGCYT on Intracellular Cadmium Level in HEI-CO Cells We investigated whether HGCYT regulate the accumulation of intracellular $\mathrm{Cd}^{2+}$ within cells. $\mathrm{Cd}^{2+}$ accumulation was determined in cells by ICP/OES and expressed as $\mathrm{g} / \mathrm{mg}$ of cell protein. We observed that treatment of $\mathrm{Cd}^{2+}$ increased the accumulation of intracellular level of $\mathrm{Cd}^{2+}$ within cells $(0.055 \pm 0.01 \mathrm{~g} / \mathrm{mg})$. However, HGCYT inhibited the accumulation of intracellular $\mathrm{Cd}^{2+}$ compare to $\mathrm{Cd}^{2+}$ alone treatment $(0.041 \pm 0.01 \mathrm{~g} / \mathrm{mg})$. The inhibition rate of $\mathrm{Cd}^{2+}$ accumulation by HGCYT $(1 \mathrm{mg} / \mathrm{ml})$ was approximately $23 \%$, but there was no significance. Figure 7 represented the relative level of intracellular $\mathrm{Cd}^{2+}$.

\section{DISCUSSION}

The findings herein show that $\mathrm{Cd}^{2+}$ induces ROS generation and cyt $c$ release. $\mathrm{Cd}^{2+}$ induces apoptosis through activation of caspase-9 and ERK in auditory HEI-OCI cells. In addition, we observed that cochlear hair cells in middle turn were damaged by $\mathrm{Cd}^{2+}$. However, HGCYT inhibited ROS generation, and activation of caspase-9 and ERK in auditory cell line. HGCYT prevented the destruction of hair cell arrays of the rat primary organ of corti explants in the presence of $\mathrm{Cd}^{2+}$.

HGCYT formula is a newly modified prescription for the purpose of development of auditory disease. HGCYT consists of 9 different herbs. Other studies reported that each medicine herb has a various effect. For example, Glycyrrhizae Radix and Zingiberis Rhizoma have been shown to prevent biological toxicity on oxidative stress through potent antioxidant and anti-lipid peroxidation activities, ${ }^{30)}$ Scutellariae Radix prevents the injury in PC12 cells. ${ }^{31)}$ It was reported that scutellaria baicalensis had the scavenging reactive oxygen species. ${ }^{32)}$ Aurantii Fructus has shown anti-shock effect, ${ }^{33)}$ and Gardeniae Fructus has been used for centrally anti-hypertension in cardiovascular system and anti-inflammation, treating parenchyma injuries. ${ }^{34)}$ HGCYT composed on the basis of the theory of Korean medicine to maximize 
its efficacy. In present study, we demonstrated the pharmacological mechanism of HGCYT in auditory cells.

Cadmium $\left(\mathrm{Cd}^{2+}\right)$ is a nonessential element widely used in industry, and is also found as a contaminant in agricultural products. ${ }^{35)} \mathrm{Cd}^{2+}$ contamination of soil and water has raised concern, because this metal is bioaccumulated in the upper levels of the food chain, including in humans, in which its biological half-life is appoproximately 20 years. ${ }^{36)}$ Given its current rate of release into the environment, $\mathrm{Cd}^{2+}$ content in the human body is likely to increase in the future, ${ }^{36)}$ which could lead to a higher incidence of $\mathrm{Cd}^{2+}$-related diseases. Liver and kidney have traditionally been considered the main targets of $\mathrm{Cd}^{2+}$ toxicity. ${ }^{37,38)}$ However, recent reports indicate that chronic exposure to low doses of $\mathrm{Cd}^{2+}$ may cause neurobehavioral problems in humans and other animals, despite a lack of detectable renal damage. ${ }^{39,40)}$ These observations emphasize the importance of studying the effects of $\mathrm{Cd}^{2+}$ in other organs. Recently, it was reported that hair cells are more sensitive to cadmium than kidney tubule cells, and that the cochlear component of hearing is more vulnerable to cadmium toxicity than other parts of the auditory system. ${ }^{6}$ ) ROS are involved in apoptosis as well as in cell proliferation. ${ }^{41)}$ ROS may be the causative factor involved in many human degenerative diseases, and antioxidants have been found to have some degree of preventive and therapeutic effects on these disorders. ${ }^{42)}$ ROS may induce cell death directly or act as intracellular messengers during cell death induced by various other kinds of stimuli. $\mathrm{Cd}^{2+}$ is reported to cause oxidative stress, i.e. increased lipid peroxidation, ROS generation and alterations in glutathione (GSH) and related enzymes, under both in vitro and in vivo conditions. ${ }^{43)}$ From this, we suggested $\mathrm{Cd}^{2+}$ enhanced ROS production might be at the root of $\mathrm{Cd}^{2+}$ toxicity. In present study, we showed that $\mathrm{Cd}^{2+}$ induced the cell death, and ROS generation. However, HGCYT inhibited $\mathrm{Cd}^{2+}$-induced cell death and ROS generation. These results suggested that anti-apoptotic effect of HGCYT is through the regulation of ROS in auditory HEIOCI cells. In addition, we investigated whether HGCYT regulate the accumulation of intracellular cadmium within cells. We observed that HGCYT inhibited the accumulation of intracellular cadmium within cells. The inhibition rate of cadmium accumulation by HGCYT $(1 \mathrm{mg} / \mathrm{ml})$ was approximately $23 \%$. This result implicated that HGCYT protected against cadmium toxicity.

Mitochondria factors such as cyt $c$, mediate the activation of pro-apoptotic proteases known as caspases. Caspase- 9 is the primary initiator caspase in a cascade that activates a number of effector caspases that cleave numerous downstream substrates that result in apoptosis. After mitochondrial outer membrane permeabilization, intermembrane space proteins including cyt $c$ are released to activate caspases in the cytoplasm. ${ }^{13)}$ Cell death initiated by caspase activation is considered to be the "classic" apoptotic pathway. In some cases, cell death is effectively blocked by caspase inhibition. Taken together, we supposed that the caspase- 9 could be an effective target for anti-apoptotic therapy in auditory cells. Therefore, we investigated whether HGCYT affects the cyt $c$ release, and caspase- 9 activation in induced by $\mathrm{Cd}^{2+}$. We showed that HGCYT abrogated $\mathrm{Cd}^{2+}$-induced cyt $c$ release, and caspase-9 activation. These results demonstrate that the anti-apoptotic effect of HGCYT, at least in part, might be de- rived through the regulation of the mitochondria pathway such as cyt $c$, and caspase-9.

MT is a ubiquitous metalloprotein found in bacteria, mammals and invertebrates. It is induced by various stressors including chemical stressor such as $\mathrm{Cd}^{2+}$. This protein has been implicated in the scavenging of heavy metal by forming linkages. Although the exact function of MT is unknown, it has been suggested MT is involved in toxic metal detoxification. We investigated whether HGCYT regulated the MT expression. As shown in Fig. 3E, treatment of $\mathrm{Cd}^{2+}$ induced the MT expression. However, we found that HGCYT did not affect the expression of MT induced by $\mathrm{Cd}^{2+}$. This result suggested that the protective effect of HGCYT could be involved in other mechanisms of MT in HEI-OC1.

MAPKs pathways are central components of the intracellular signaling networks that control many aspects of mammalian cellular physiology including cell proliferation, differentiation, and apoptosis. ${ }^{19)}$ In general, the ERK cascade is activated by growth factors and is associated with cell survival and proliferation. ${ }^{19,20)}$ On the other hand, p38 and JNK are mainly activated by cellular stress and are often associated with inflammation and apoptosis. However, cumulative reports have indicated that these signaling pathways exhibit more complex roles in the regulation of distinct cellular effects. The cellular functions regulated by ERK, p38 or JNK seem to depend on the cell type, the stimulus, the duration and strength of kinase activities. ${ }^{20,44)}$ Studies recently reported that JNK activation is involved in $\mathrm{Cd}^{2+}$-induced apoptosis in J774A.1. Their study showed that $\mathrm{Cd}^{2+}$ increased activation of JNK, but decreased the activation of p38. ${ }^{23)}$ Iryo et al. reported that ERK1/2 was responsible for toxicity of $\mathrm{Cd}^{2+}$, in which experiment U0126 was used as an ERK1/2 inhibitor. $^{21)}$ In their study, pretreatment with U0126 suppressed $\mathrm{Cd}^{2+}$-induced ERK activation and the apoptosis, whereas the inhibition of p38 kinase activity with SB203580 did not protect cells from apoptosis. The ERK1/2 pathway was not responsible for $\mathrm{Cd}^{2+}$-induced cytotoxicity of CL3 cells, a lung carcinoma cell line. This discrepancy may be due to the cell type difference. In present study, we observed that ERK inhibitor suppressed the cell death. From this reasons, we speculated that $\mathrm{Cd}^{2+}$ induced the apoptosis through the ERK activation, and examined whether $\mathrm{Cd}^{2+}$ affected the ERK activation in HEI-OC1. We showed that $\mathrm{Cd}^{2+}$ increased the ERK activation. However, HGCYT suppressed ERK activation induced by $\mathrm{Cd}^{2+}$. These results suggest that the ERK pathway may be a potential therapeutic target to prevent ototoxic damage from $\mathrm{Cd}^{2+}$. Although HGCYT attenuated ERK activation, the effect of HGCYT on other pathways involving MAPK upstream and downstream was not elucidated in the present study. Thus, further investigation is necessary to clarify the role of HGCYT on the MAPK pathway in the auditory system.

It is reported that $\mathrm{Cd}^{2+}$ causes hearing loss in rat and mainly impairs the cochlea without affecting the central auditory pathways. ${ }^{6)}$ The cochlea component of hearing is more vulnerable to $\mathrm{Cd}^{2+}$ toxicity than other parts of the auditory system. In present study, we investigated whether $\mathrm{Cd}^{2+}$ affects the rat primary organ of Corti explants, and HGCYT protects the injury of primary organ of Corti explants from $\mathrm{Cd}^{2+}$. The middle turn of the organ of Corti from rats was isolated and treated with $\mathrm{Cd}^{2+}$ in the absence or presence of 
HGCYT. Incubation media alone did not result in any injury of stereocilia bundles, in which F-actin was intensely labeled with TRITC-conjugated phalloidin. Three rows of outer hair cells and a single row of inner hair cells (IHCs) were clearly observed in control culture of the rat primary organ of Corti explants. We observed that $\mathrm{Cd}^{2+}$ destructed the orderly arrangements of the three rows of OHCs and a single row of IHCs in middle turn. These data showed that hair cells were damaged by $\mathrm{Cd}^{2+}$. However, pretreatment with the HGCYT, completely prevented the destruction of hair cell arrays of the rat primary organ of Corti explants in the presence of $\mathrm{Cd}^{2+}$.

In conclusion, we have shown that HGCYT inhibited $\mathrm{Cd}^{2+}$-induced cell death, ROS generation, cyt $c$ release, and activation of caspase-9, and ERK in auditory cells. In addition, HGCYT prevented the destruction of hair cell arrays of the rat primary organ of Corti explants in the presence of $\mathrm{Cd}^{2+}$. These data are an important contribution in elucidating the pharmacological mechanism of HGCYT and potential treatment therapies of $\mathrm{Cd}^{2+}$-induced ototoxicity.

Acknowledgements This work was supported by the Ministry of Science \& Technology $(\mathrm{MoST}) /$ Korea Science \& Engineering Foundation (KOSEF) through the Vestibulocochlear Research Center (VCRC) at Wonkwang University (R13-2002-055-00000-0).

\section{REFERENCES}

1) Anniko M., Acta Otolaryngol. (Stockh.), 82, 70-81 (1976).

2) Hoeffding V., Fechter L. D., Neurotoxicol. Teratol., 13, 135-145 (1991).

3) Rybak L. P., Otolaryngol. Head Neck Surg., 106, 677-686 (1992).

4) Blakeley B. W., Myers S. F., Otolaryngol. Head Neck Surg., 109, 385-391 (1993).

5) Fausti S. A., Henry J. A., Schaffer H. I., Olson D. J., Frey R. H., Bagby G. C. Jr., Arch. Otolaryngol. Head Neck Surg., 119, 661-666 (1993).

6) Ozcaglar H. U., Agirdir B., Dinc O., Turhan M., Kilincarslan S., Oner G., Acta Otolaryngol. Apr., 121, 393-397 (2001).

7) Lemarie A., Lagadic-Gossmann D., Morzadec C., Allain N., Fardel O., Vernhet L., Free Radic. Biol. Med., 36, 1517-1531 (2004).

8) Pathak N., Khandelwal S., Toxicology, 220, 26-36 (2006).

9) Pathak N., Khandelwal S., Toxicology Lett., 165, 121-132 (2006).

10) Pulido M. D., Parrish A. R., Mutat. Res., 533, 227-241 (2003).

11) Tsujimoto Y., J. Cell. Physiol., 195, 158-167 (2003).

12) Kim M. S., Kim B. J., Woo H. N., Kim K. W., Kim K. B., Kim I. K., Jung Y. K., Toxicology, 145, 27-37 (2000).

13) Li M., Kondo T., Zhao Q. L., Li F.-J., Tanabe K., Arai Y., Zhou Z.-C., Kasuya M., J. Biol. Chem., 275, 39702-39709 (2000).

14) Kondoh M., Araragi S., Sato K., Higashimoto M., Takiguchi M., Sato M., Toxicology, 170, 111-117 (2002).
15) Ishido M., Ohtsubo R., Adachi T., Kunimoto M., Environ. Health Perspect., 110, 37-42 (2002).

16) Harstad E. B., Klaassen C. D., Toxico. Appl. Pharmacol., 179, 155162 (2002).

17) Shih C. M., Wu J. S., Ko W. C., Wang L. F., Wei Y. H., Liang H. F., Chen Y. C., Chen C. T., J. Cell. Biochem., 89, 335-347 (2003).

18) Schaeffer H. J., Weber M. J., Mol. Cell. Biol., 19, 2435-2444 (1999).

19) Lewis T. S., Shapiro P. S., Ahn N. G., Adv. Cancer Res., 74, 49-139 (1998).

20) Puddicombe S. M., Davies D. E., Clin. Exp. Allergy, 30, 7-11 (2000).

21) Iryo Y., Matsuoka M., Wispriyono B., Sugiura T., Igisu H., Biochem. Pharmacol., 60, 1875-1882 (2000).

22) Chuang S. M., Yang J. L., Mol. Cell. Biochem., 222, 85-95 (2001).

23) Kim J., Sharma R. P., Kim J. Y., Toxicol. Sci., 81, 518-527 (2004).

24) Kalinec G. M., Webster P., Lim D. J., Kalinec F., Audiol. Neurootol., 8, 177-189 (2003).

25) Kim M. S., Lim W. K., Cha J. G., An N. H., Yoo S. J., Park J. H., Kim H. M., Lee Y. M., Cancer Lett., 171, 79-85 (2001).

26) Zheng J. L., Gao W. Q., Eur. J. Neurosci., 8, 1897-1905 (1996)

27) Garrido C., Galluzzi L., Brunet M., Puig P. E., Didelot C., Kroemer G., Cell Death Differ., 13, 1423-1433 (2006).

28) Ziegler E. A., Brieger J., Heinrich U.-R., Mann W. J., ORL, 66, $297-$ 301 (2004).

29) Kroemer G., Martin S. J., Nat. Med., 11, 725-730 (2005).

30) Rhyu D. Y., Kang K. S., Sekiya M., Yokozawa T., Am. J. Chin. Med., 35, 127-137 (2007).

31) Shang Y. Z., Qin B. W., Cheng J. J., Miao H., Phytother. Res., 20, $53-$ 57 (2006).

32) Shao Z. H., Vanden Hoek T. L., Li C. Q., Schumacher P. T., Becker L. B., Chan K. C., Qin Y., Yin J. J., Yuan C. S., Am. J. Chin. Med., 32, 89-95 (2004).

33) Zhao X. W., Li J. X., Zhu Z. R., Sun D. Q., Liu S. C., Chin. Med. J., (Engl.) 102, 91-93 (1989).

34) Ni H. Y., Zhang Z. H., Fu H. Z., Zhongguo Zhong Yao Za Zhi, 31, 538-541 (2006).

35) Stoeppler M., "Metals and Their Compounds in the Environment. Occurrence, Analysis, and Biological Relevance," VCH, Weinheim, New York, Basel, Cambridge, 1991, pp. 803-851.

36) Satarug S., Baker J. R., Urbenjapol S., Haswell-Elkins M., Reilly P. E., Williams D. J., Moore M. R., Toxicol. Lett., 137, 65-83 (2003).

37) Nishijo M., Morikawa Y., Nakagawa H., Tawara K., Miura K., Kido T., Ikawa A., Kobayashi E., Nogawa K., Occup. Environ. Med., 63, 545550 (2006).

38) Horiguchi H., Oguma E., Kayama F., Arch. Toxicol., 80, 680-686 (2006).

39) Leret M. L., Millan J. A., Antonio M. T., Toxicology, 186, 125-130 (2003).

40) Viaene M. K., Masschelein R., Leenders J., De G. M., Swerts L. J., Roels H. A., Occup. Environ. Med., 57, 19-27 (2000).

41) Mates J. M., Sanchez-Jimenez F. M., Int. J. Biochem. Cell Biol., 32, $157-170$ (2000)

42) Ames B. N., Shigenaga M. K., Hagen T. M., Proc. Natl. Acad. Sci. U.S.A., 90, 7915-7922 (1993)

43) Hart B. A., Lee C. H., Shukla G. S., Shukla A., Osier M., Eneman J. D., Chiu J. F., Toxicology, 133, 43-58 (1999).

44) Nebreda A. R., Porras A., Trends Biochem. Sci., 25, 257-260 (2000). 